\title{
Corrigendum: Regulatory and policy implications of sand mining along shallow waters of Nzhelele River in South Africa
}

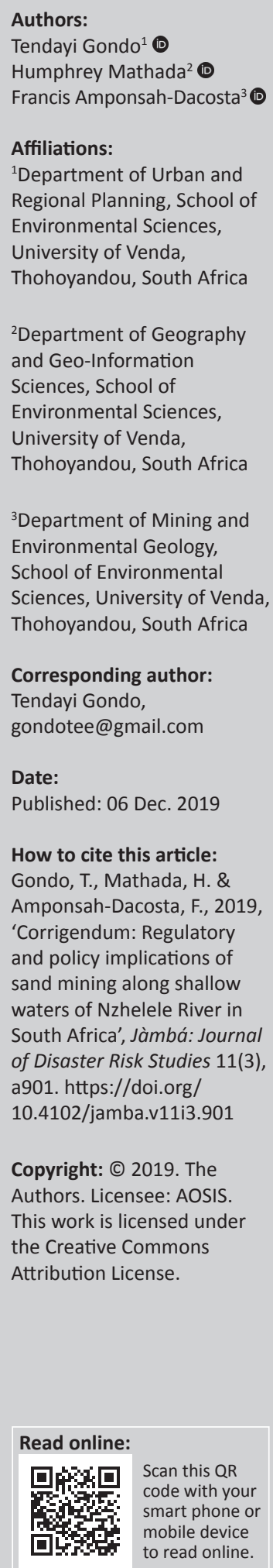

Scan this QR code with your smart phone or smart phone or mobile device to read online.

In the version of this article published earlier, the name of the river Nzhelele was incorrectly spelt as Njelele. The river name has been corrected in the article title and in the 'How to cite this article' section. The authors apologise for any inconvenience caused. 